\title{
O TRABALHO DOS MÚSICOS: ANÁLISE DAS QUEIXAS MUSCULOESQUELÉTICAS E SUAS RELAÇÕES COM A PRÁTICA INSTRUMENTAL
}

\section{THE MUSICIANS WORK: ANALYSIS OF MUSCULOSKELETAL COMPLAINTS AND ITS RELATIONS WITH THE PRACTICAL INSTRUMENT}

\author{
Clarissa Stefani Teixeira \\ Universidade Federal de Santa Catarina \\ Programa de Pós-Graduação em Engenharia de Produção \\ Bairro Trindade, CEP: 88040-970 - Florianópolis, Santa Catarina \\ Fausto Kothe \\ Universidade Federal do Paraná \\ Programa de Pós-Graduação em Música \\ Bairro Batel, CEP: 80420-170 - Curitiba, Paraná \\ Érico Felden Pereira \\ Universidade Federal do Paraná \\ Programa de Pós-Graduação em Educação Física \\ Bairro: Jardim Botânico, CEP: 80215-370 - Curitiba, Paraná

\section{Leila Amaral Gontijo} \\ Universidade Federal de Santa Catarina \\ Programa de Pós-Graduação em Engenharia da Produção \\ Bairro Trindade, CEP: 88040-970 - Florianópolis, Santa Catarina

\section{Eugenio Andrés Díaz Merino} \\ Universidade Federal de Santa Catarina \\ Programa de Pós-Graduação em Engenharia da Produção \\ Bairro Trindade, CEP: 88040-970 - Florianópolis, Santa Catarina
}

\section{RESUMO}

Os acometimentos musculoesqueléticos estão presentes na profissão dos músicos. Muitas vezes, as queixas de dor e desconforto são relacionadas aos afastamentos das atividades instrumentais. Porém, essas associações ainda não são esclarecidas pela literatura, principalmente em âmbito nacional. Logo, o presente estudo buscou analisar as associações entre as queixas musculoesqueléticas e os afastamentos em função dessas queixas em músicos de orquestra. O estudo foi realizado com 20 músicos de uma orquestra da região Sul do 
Brasil. Os instrumentistas responderam ao questionário Nórdico e a um questionário com perguntas abertas que identificou os aspectos sociodemográficos, de saúde e de trabalho. Os aspectos foram associados às queixas musculoesqueléticas nos últimos 12 meses, 7 dias e aos afastamentos da profissão em função das queixas. Os resultados ilustram relações moderadas entre a idade, gênero, tempo e frequência de prática instrumental com as queixas musculoesqueléticas relatadas pelos músicos. Além disso, o tipo de instrumento tocado também está relacionado às queixas, sendo os músicos de cordas aqueles com maiores tendências de ter queixas.

Palavras-chave: trabalho, prática instrumental, músicos, orquestra, queixas musculoesqueléticas.

\begin{abstract}
The musculoskeletal involvements are present in the profession of musicians. Many times the complaints of pain and discomfort are related to the removal of instrumental activities. However, these associations are still not clarified in the literature. Therefore, this study examined the associations between musculoskeletal complaints and removals due to these complaints in the orchestra musicians. The study was performed with an orchestra of 20 musicians from southern Brazil. The players responded to the Nordic questionnaire and a questionnaire with open questions that identified the socio-demographic, health and work aspects. The aspects were related to musculoskeletal complaints in the last 12 months, 7 days and the removals of the profession due to complaints. The results show moderate relationship between age, gender, frequency of instrumental practice time to the musculoskeletal complaints reported by musicians. In addition, the type of instrument played is also related to complaints and the strings musicians with higher tendencies to take complaints.
\end{abstract}

Key-words: work, instrumental practice, musicians, orchestra, musculoskeletal complaints..

\title{
1 INTRODUÇÃO
}

As práticas instrumentais dos músicos podem causar problemas físicos e desconfortos musculoesqueléticos que se constituem em situações de risco para os afastamentos profissionais, em um contexto de adoecimento permeado, tanto por fatores individuais, quanto ocupacionais e ambientais (ZAZA, CHARLES e MUSZYNSKI, 1998; SCHUELE e LEDERMAN, 2004; HANSEN e REED, 2006). Os adoecimentos musculoesqueléticos dos músicos, conforme abordam Bejjani, Kaye e Beham (1996), podem comprometer significativamente a habilidade e o desempenho profissional, principalmente pelo alto grau de precisão técnica necessário para o desenvolvimento das atividades com o instrumento.

As investigações com saúde ocupacional dos músicos têm destacado a importância das análises das posturas adotadas, a tensão ao tocar, a força utilizada, o tempo excessivo de 
dedicação ao instrumento, as condições de iluminação, ruído e temperatura, as características do mobiliário, a troca de instrumento, técnica utilizada e a familiarização com o repertório, com objetivo de propor medidas preventivas para o adoecimento desta população (BLUM e AHTERS, 1994; NORRIS, 1997; POTTER e JONES, 1995; HANSEN e REED, 2006; HEMING; 2004; MENDES, CATAI e ALBERTI, 2009).

No âmbito da prevenção secundária e terciária as preocupações com esse público voltam-se à continuidade das atividades que, muitas vezes, não é possível devido às lesões que levam ao afastamento (TEIXEIRA et al., 2009a). Mesmo que os afastamentos estejam presentes na profissão, poucos são os estudos, principalmente em âmbito nacional, que relacionam os afastamentos e as queixas musculoesqueléticas de forma a entender as associações existentes nas diferentes regiões corporais.

Diante dessas premissas, o presente estudo buscou analisar as associações entre as queixas musculoesqueléticas e os afastamentos em função dessas queixas em músicos de orquestra.

\section{METODOLOGIA}

Este estudo caracteriza-se, segundo Thomas e Nelson (2002), como um estudo descritivo-exploratório, de corte transversal, no qual foi realizado um levantamento de informações ainda pouco investigadas em uma determinada população.

O estudo foi realizado em 2008, com músicos de uma orquestra semi-profissional da região Sul do Brasil. Esta orquestra é composta por 29 músicos sendo estes trabalhadores dos seguintes instrumentos: cordas (violino, viola, violoncelo, contrabaixo e violão), madeiras (flauta transversa e clarinete) e metais (trompete e trombone).

Do total de 29 músicos, 20 responderam ao questionário Nórdico para identificação da presença de queixas musculoesqueléticas. Este instrumento foi adaptado culturalmente para a língua portuguesa por Barros e Alexandre (2003), apresentando uma confiabilidade variando de 0,88 a 1 segundo o coeficiente de Kappa e validado por Pinheiro, Tróccoli e Carvalho (2002) mostrando bom índice de validade concorrente para a versão brasileira.

Este questionário (auto aplicado) apresenta uma figura humana vista de costas, dividida em regiões anatômicas: cervical, ombros, cotovelos, punhos/mãos, região superior das costas, região inferior das costas (lombar), quadril/coxas, joelhos, tornozelos/pés. As questões relacionadas a cada área anatômica verificam a presença de dores nos últimos 12 
meses e nos últimos sete dias. Esse instrumento investiga, também, se os indivíduos ficaram impedidos de exercer suas atividades normais e se houve necessidade de impedimento das atividades profissionais, ou seja, os afastamentos das atividades. Considerando-se a utilização do questionário Nórdico optou-se por definir sintomas osteomusculares/musculoesqueléticos como o auto-relato de dor, formigamento ou dormência em nove diferentes regiões corporais (BARROS; ALEXANDRE, 2003).

A aplicação dos instrumentos foi realizada em sessões individuais, nos locais de trabalho dos indivíduos, após autorização dos responsáveis pela orquestra e com a concordância dos músicos, que foram informados sobre os objetivos do estudo e assinaram o Termo de Consentimento Livre e Esclarecido, sendo as informações mantidas em sigilo, preservando os princípios éticos com base na resolução ${ }^{\circ}$ 196, de 10 de outubro de 1996, do Conselho Nacional de Saúde (CNS).

Para a identificação de possíveis fatores associados aos sintomas musculoesqueléticos dos músicos, foi elaborado um questionário multidimensional que constou dos itens relacionados aos aspectos sociodemográficos, de saúde e ao trabalho, sendo assim definidos:

1) Aspectos sociodemográficos: basearam-se na idade, gênero, estado civil e grau de instrução;

2) Aspectos de saúde: basearam-se nas práticas de exercícios físicos realizadas, frequência da prática de exercícios físicos, uso de medicamentos para as queixas de dor/desconforto e busca por diagnósticos médicos em função das queixas;

3) Aspectos de trabalho: basearam-se no tipo de instrumento tocado (cordas ou sopros), tempo em que se toca na orquestra, frequência semanal de dedicação ao instrumento (horas de estudo) no que tange aos horários e dias na semana, dedicação a outro instrumento além daquele utilizado na orquestra.

Para a análise dos dados foi realizada a estatística descritiva por meio da média, desvio padrão para as variáveis contínuas e para as variáveis categóricas foi realizada a distribuição de frequência absoluta e relativa. Foram realizadas associações entre os afastamentos, queixas nos últimos 12 meses e sete dias e os aspectos sociodemográficos, de saúde e de condições de trabalho. Para essas associações foi utilizada a análise de correlação de Spearman. O nível de significância adotado para todos os testes foi de 5\%. Para a análise dos dados foi utilizado o programa estatístico SPSS 11.5 for Windows. 
Para efeito de análise foi considerado o critério adotado por Malina (1996) que descreve correlação baixa para um valor menor que 0,30 , moderada para valores entre 0,30 e 0,60 e alta para valores superiores a 0,60 .

\section{RESULTADOS}

Dos indivíduos estudados $75 \%(n=15)$ eram do gênero masculino. O tempo de prática com o instrumento foi, no mínimo, um ano e, no máximo 47 anos, sendo a média de 7,75 \pm 10,83 anos. Com a orquestra avaliada foram observadas práticas de 3,52 $\pm 0,68$ anos e práticas coletivas de 3,64 $\pm 0,49$ horas destinadas à participação da orquestra. O tempo de práticas diárias foi de 2,05 \pm 1,61 horas, com uma frequência de 5,25 \pm 1,52 dias na semana. Além das práticas com o instrumento, $70 \%(\mathrm{n}=14)$ dos músicos afirmaram realizar práticas com outro instrumento não considerando o tocado na orquestra.

Com relação às questões de saúde, a prática de exercícios físicos era realizada por $65 \%$ $(n=13)$ dos músicos, com frequências de práticas de 3,62 \pm 1,61 dias na semana. Porém, nenhuma das modalidades realizadas era desenvolvida juntamente com as atividades da orquestra, uma vez que a mesma não possui programas para a prática de exercícios como, por exemplo, a ginástica laboral. Durante a jornada de trabalho, foi observado que apenas $5 \%$ dos músicos realizam alongamentos antes e depois dos ensaios (coletivos, de naipe) e dos estudos individuais. Com relação ao diagnóstico clínico apenas $30 \%(n=6)$ dos músicos afirmaram possuir. Já o uso de medicamentos para as queixas musculoesqueléticas é realizado por $40 \%$ $(\mathrm{n}=8)$ dos instrumentistas avaliados.

As análises apontaram que $90 \%(\mathrm{n}=18)$ dos instrumentistas relataram dores nos últimos 12 meses de prática e 45\% (n=9) dos instrumentistas referiram queixas nos últimos sete dias em alguma região do corpo. Os indivíduos acometidos nos últimos 12 meses indicaram queixas em 3,28 $\pm 2,76$ regiões do corpo (mínimo de uma (1) região e no máximo 11 regiões acometidas). Já aqueles com queixas nos últimos sete dias as regiões foram em $2 \pm$ 1,58 (com no mínimo uma (1) região acometida e no máximo cinco regiões). Com relação aos afastamentos, $45 \%(n=9)$ dos instrumentistas foram impedidos de desenvolver suas atividades em função das queixas em $2 \pm 1,80$ regiões corporais (com no máximo seis regiões corporais afetadas).

Considerando os afastamentos em função das queixas musculoesqueléticas e os fatores associados (aspectos sociodemográficos, de saúde e de trabalho) não foram encontradas 
correlações estatisticamente significativas. As associações encontradas no presente estudo foram relacionadas às queixas e alguns dos fatores associados, como por exemplo, a idade, o gênero, o tempo e a frequência semanal de práticas. Não foram observadas correlações entre o estado civil, grau de instrução, prática de exercício físico, uso de medicamentos para as queixas e dedicação a outro instrumento musical.

De forma geral, os afastamentos tiveram associações com as queixas nos últimos 12 meses e sete dias considerando algumas regiões corporais. Na Tabela 1 foram apresentados os resultados das correlações estatisticamente significativas relacionando os aspectos sociodemográficos, de saúde e de trabalho com as queixas musculoesqueléticas nas diferentes regiões corporais nos últimos 12 meses.

Tabela 1 - Associações dos aspectos sociodemográficos, de saúde e de trabalho com as queixas musculoesqueléticas nas diferentes regiões corporais nos últimos 12 meses.

\begin{tabular}{|c|c|c|c|c|c|c|c|}
\hline \multirow[b]{2}{*}{ Aspectos } & \multicolumn{7}{|c|}{ Regiões corporais } \\
\hline & & Pescoço & $\begin{array}{l}\text { Ombro } \\
\text { direito }\end{array}$ & $\begin{array}{c}\text { Cotovelo } \\
\text { direito }\end{array}$ & $\begin{array}{l}\text { Punho } \\
\text { esquerdo }\end{array}$ & $\begin{array}{c}\text { Costas } \\
\text { superior }\end{array}$ & $\begin{array}{l}\text { Costas } \\
\text { inferior }\end{array}$ \\
\hline \multirow{2}{*}{ Idade } & $\mathrm{r}$ & $-0,480$ & $-0,448$ & - & - & - & - \\
\hline & $\mathrm{p}^{*}$ & 0,032 & 0,047 & - & - & - & - \\
\hline \multirow{2}{*}{ Gênero } & $\mathrm{r}$ & - & - & - & $-0,471$ & - & - \\
\hline & $\mathrm{p}^{*}$ & - & - & - & 0,036 & - & - \\
\hline \multirow{2}{*}{ Tempo de prática por dia } & $\mathrm{r}$ & - & - & 0,535 & - & - & - \\
\hline & $\mathrm{p}^{*}$ & - & - & 0,015 & - & - & - \\
\hline \multirow{2}{*}{$\begin{array}{l}\text { Frequência semanal de } \\
\text { práticas }\end{array}$} & $\mathrm{r}$ & - & - & - & - & - & $-0,452$ \\
\hline & $\mathrm{p}^{*}$ & - & - & - & - & - & 0,045 \\
\hline \multirow{2}{*}{ Diagnóstico clínico } & $\mathrm{r}$ & - & - & - & - & - & $-0,491$ \\
\hline & $\mathrm{p}^{*}$ & - & - & - & - & - & 0,028 \\
\hline \multirow{2}{*}{$\begin{array}{l}\text { Tipo de instrumento } \\
\text { tocado }\end{array}$} & $\mathrm{r}$ & - & - & - & - & $-0,538$ & - \\
\hline & $\mathrm{p}^{*}$ & - & - & - & - & 0,014 & - \\
\hline
\end{tabular}

* Valor menor que 0,05 indica diferença estatisticamente significativa.

De acordo com os resultados apresentados na Tabela 1, quando observado a relação entre as queixas musculoesqueléticas e os aspectos, nos últimos 12 meses, foram encontradas associações negativas entre a idade e o gênero. Com relação à idade as associações foram de forma que quanto maior a idade, menores são as queixas na região do pescoço e ombro direito. Já o gênero mostrou associações maiores em ser do gênero feminino para a presença de queixas. O tempo de prática esteve associado às queixas na região do cotovelo de forma que quanto maior o tempo de prática maior as queixas nesta região. Já a frequência semanal 
esteve associada de forma que aqueles que dedicam menos horas às atividades mostram-se com mais queixas na região inferior das costas. O diagnóstico clínico mostrou-se importante uma vez que aqueles que o obtiveram foram os que apresentaram queixas musculoesqueléticas na região inferior das costas nos últimos 12 meses. O tipo de instrumento tocado demonstrou que as maiores associações entre queixas na região superior das costas estão para os instrumentistas de cordas.

Nos últimos sete dias de práticas com o instrumento, apenas os aspectos sociodemográficos (idade) e os aspetos de trabalho (tempo de práticas por dia e frequência semanal de prática) mostraram-se associados às queixas musculoesqueléticas nas diferentes regiões corporais e estas relações podem ser visualizadas na Tabela 2.

Tabela 2 - Associação entre as queixas musculoesqueléticas nos últimos sete dias os aspectos sociodemográficos (idade) e de trabalho (tempo de prática por dia e frequência semanal de prática) dos músicos.

\begin{tabular}{cccccc}
\hline \multirow{2}{*}{ Aspectos } & \multicolumn{5}{c}{ Regiões corporais } \\
\cline { 2 - 6 } & & Pescoço & Ombros & Punhos & $\begin{array}{c}\text { Costas } \\
\text { superior }\end{array}$ \\
\hline \multirow{2}{*}{ Idade } & $\mathrm{r}$ & - & $-0,502$ & - & - \\
& $\mathrm{p}^{*}$ & - & 0,024 & - & - \\
Tempo de prática por dia & $\mathrm{r}$ & - & - & - & 0,516 \\
& $\mathrm{p}^{*}$ & - & - & - & 0,020 \\
Frequência semanal de prática & $\mathrm{r}$ & 0,553 & 0,464 & 0,553 & 0,464 \\
& $\mathrm{p}^{*}$ & 0,011 & 0,039 & 0,011 & 0,039 \\
\hline
\end{tabular}

A idade se mostrou com associações de forma que quanto maior a idade menor é a tendência de se ter queixas na região dos ombros, ou seja, a idade mostrou correlação inversa com a tendência de queixas na região dos ombros. As regiões dos ombros, punhos, pescoço e superior das costas mostraram-se associados à maior frequência semanal e ao maior tempo de prática diária no caso da região superior das costas.

As relações entre as queixas musculoesqueléticas nos últimos 12 meses e os afastamentos em função das queixas estão ilustradas na Tabela 3. 
Tabela 3 - Associações entre as queixas nas diferentes regiões corporais, nos últimos 12 meses, e os afastamentos gerados pelas queixas musculoesqueléticas.

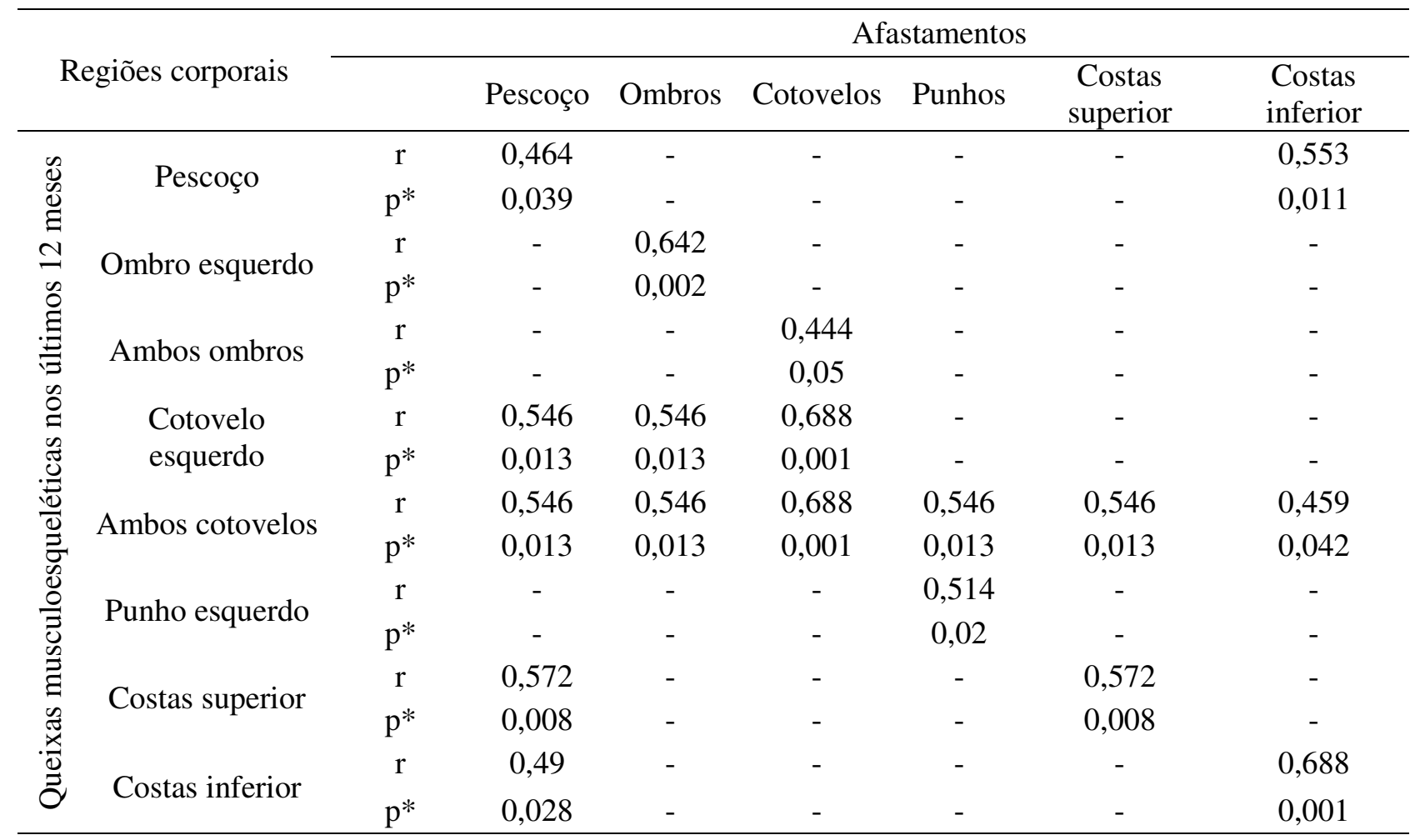

* Valor menor que 0,05 indica diferença estatisticamente significativa.

De acordo com os resultados ilustrados na Tabela 3 se pode observar que a região corporal dos cotovelos foi a que mais apresentou associações com os afastamentos nas diversas regiões corporais. Além disso, os afastamentos estão associados às queixas nas diversas regiões corporais, ou seja, os músicos que se mostraram acometidos nos últimos 12 meses, em determinada região, apresentaram correlação significativa para os afastamentos na mesma região.

Já a Tabela 4 ilustra as associações entre as queixas musculoesqueléticas nos últimos sete dias e os afastamentos em função dessas queixas. 
Tabela 4 - Associações entre as queixas nas diferentes regiões corporais, nos últimos sete meses, e os afastamentos gerados pelas queixas musculoesqueléticas.

\begin{tabular}{|c|c|c|c|c|c|}
\hline \multirow{2}{*}{\multicolumn{2}{|c|}{ Regiões corporais }} & & \multicolumn{3}{|c|}{ Afastamentos } \\
\hline & & & Ombros & \multirow{2}{*}{$\begin{array}{c}\text { Punhos } \\
-\end{array}$} & \multirow{2}{*}{$\begin{array}{c}\text { Costas inferior } \\
-\end{array}$} \\
\hline \multirow{8}{*}{ 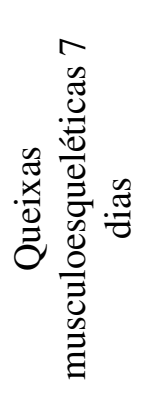 } & \multirow{2}{*}{ Pescoço } & $\mathrm{r}$ & 0,490 & & \\
\hline & & $\mathrm{p}^{*}$ & 0,028 & - & - \\
\hline & \multirow{2}{*}{ Ombros } & $\mathrm{r}$ & 0,608 & - & - \\
\hline & & $\mathrm{p}^{*}$ & 0,004 & - & - \\
\hline & \multirow{2}{*}{ Punhos } & $\mathrm{r}$ & 0,490 & 0,490 & - \\
\hline & & $\mathrm{p}^{*}$ & 0,028 & 0,028 & - \\
\hline & \multirow{2}{*}{ Costas inferior } & $\mathrm{r}$ & - & - & 0,667 \\
\hline & & $\mathrm{p}^{*}$ & - & - & 0,001 \\
\hline
\end{tabular}

* Valor menor que 0,05 indica diferença estatisticamente significativa.

Diferentemente dos resultados encontrados para os 12 meses, parece que nos últimos sete dias de práticas as queixas permaneceram correlacionadas apenas na região dos ombros, punhos e inferior das costas, sendo que o ombro mostrou associação com todas as queixas musculoesqueléticas, ou seja, ombros, punhos, região inferior das costas e pescoço.

De forma geral, as correlações podem ser consideradas como sendo moderadas, segundo o critério de Malina (1996). As associações mais fortes encontradas, segundo o mesmo critério, foram em se estar afastado por uma região corporal e relatar queixas musculoesqueléticas, tanto os últimos 12 meses, quanto nos últimos sete dias na mesma região corporal. Porém, também foram encontradas associações entre as outras regiões o que pode ser justificado pela musculatura atuante durante a prática instrumental que não é feita de forma isolada, mas sim de forma que toda a musculatura da região superior do tronco funcione de forma concêntrica, excêntrica e isométrica para o desenvolvimento da obra musical.

\section{DISCUSSÃO}

Os resultados encontrados mostraram associações entre os aspectos sociodemográficos (idade e gênero), de trabalho (tempo e frequência de prática instrumental) e de saúde (se ter um diagnóstico médico), o que demonstra influências desses aspetos sobre as atividades instrumentais desenvolvidas pelos músicos. 
De maneira geral, as indicações de que os músicos estão entre um grupo de risco ocupacional já estão sendo evidenciados principalmente pela literatura internacional (ENGQUIST, ØRBAEK e JAKOBSSON, 2004). Segundo uma revisão sistemática realizada por Zazá (1998) as prevalências de desordens musculoesqueléticas em músicos estão entre $39 \%$ a $87 \%$ em indivíduos adultos. Mais recentemente, Hansen e Reed (2006) indicaram que acometimentos em músicos têm prevalências de problemas físicos na ordem de $50 \%$ a $80 \%$. Frank e Mühlen (2007) sugeriram que as disfunções musculoesqueléticas relacionadas à prática instrumental são frequentes entre músicos, atingindo acima de $70 \%$ dos componentes de orquestras. No estudo de Roset-Liobet, Rosinés-Cubells e Saló-Orfila (2000) 77,9\% dos avaliados passaram por problemas de saúde e $37,3 \%$ destes sentiram que a habilidade para as práticas instrumentais foi afetada.

Wu (2007) indica que a etiologia das desordens musculoesqueléticas é um fator multifatorial. Neste sentido, as influências do gênero, tempo de experiência com o instrumento, tempo de prática com o instrumento, tipo de instrumento e falta de repouso são alguns dos condicionantes para as queixas musculoesqueléticas. De acordo com os resultados encontrados pelo presente estudo, pode-se observar que os aspectos sociodemográficos (como a idade e o gênero), de saúde e de trabalho (como o tempo de experiência, prática e tipo de instrumento) investigados não se relacionaram aos afastamentos e sim às queixas musculoesqueléticas, o que demonstra que também há necessidade de investigar as associações entre as queixas e os afastamentos.

Um fato interessante de se salientar é com relação à idade onde aqueles mais jovens apresentaram uma maior tendência em se ter queixas, tanto nos últimos 12 meses quanto nos últimos sete dias. Estes fatos vão de encontro aos resultados encontrados no estudo de RosetLiobet, Rosinés-Cubells e Saló-Orfila (2000) que identificaram fatores de risco do trabalho dos músicos com aumento da idade (entre 31 e 40 anos). Estas relações, segundo os autores, são pelos motivos que os músicos considerados profissionais são mais velhos e estes tocam mais horas por dia durante mais tempo. Logo, estas considerações também podem estar ocorrendo nos músicos avaliados, uma vez que os mesmos podem ser considerados como semi-profissionais.

Os diferentes níveis técnicos da profissão já foram relacionados em outros estudos. Lederman (2003), por exemplo, faz inferências dos diferentes níveis de músicos, como profissionais, professores e estudantes, que representam um grupo comum para os acometimentos de problemas neuromusculares relacionados à prática instrumental. Estas 
indicações relacionam-se a idade, mesmo que esta não tenha sido determinada pelo autor. Steinmetz, Seidel e Niemier (2008) indica presença de dores musculoesqueléticas já a partir dos 13 anos de idade, o que se relaciona às indicações de Sadeghi et al. (2004) onde a idade de se começar a tocar um instrumento musical é um fator que contribui para os acometimentos.

Com relação ao gênero o estudo de Roset-Liobet, Rosinés-Cubells e Saló-Orfila (2000) e de Engquist, Ørbaek e Jakobsson (2004) não observou diferenças entre as queixas musculoesqueléticas quando relacionado ao gênero dos músicos. Porém, no estudo de RosetLiobet, Rosinés-Cubells e Saló-Orfila (2000) houve predominância de os homens estarem no grupo daqueles que sofreram por mais de cinco anos, já as mulheres foram relacionadas aquelas que apresentaram queixas em um período menor de tempo.

Observando os resultados de outras pesquisas entre músicos profissionais, percebe-se a predominância do gênero feminino no grupo dos indivíduos com maiores problemas musculoesqueléticos (MIDDLESTADT e FISHBEIN, 1989; ZAZA e FAREWELL, 1997; LEDERMAN, 2003; FRANK e MÜHLEN, 2007). Fishbein e Middlestadt (1988) reportam valores superiores em musicistas de cordas, o que também se associa aos resultados aqui encontrados, uma vez que houve tendência dos instrumentistas de cordas serem os mais acometidos (Tabela 1). Esta tendência também se manteve em contrabaixistas do gênero feminino, que também são instrumentistas de cordas. Logo, assim como afirmam Frank e Mühlen (2007), estas considerações levam a conclusão de que o gênero é predisponente para o desenvolvimento dessas queixas, sendo as mulheres aquelas com maior possibilidade de acometimentos.

Assim, Lederman (2003) reportou que dos 1353 instrumentistas avaliados (mesmo sendo os homens a maioria) 60\% das mulheres eram acometidas. Roset-Liobet, RosinésCubells e Saló-Orfila (2000) reportaram diferenças entre as queixas dos homens e mulheres, sendo que os homens reclamaram de inflamação e câimbras, enquanto que as mulheres reclamaram de inchaço, tensão e rigidez muscular.

As causas para estas consequências podem estar relacionadas à antropometria diferenciada entre homens e mulheres que tocam instrumentos com mesmas dimensões. Outras indicações são relacionadas à menor força muscular, menor amplitude da mão e maior ocorrência de hipermobilidade articular entre mulheres (FISHBEIN e MIDDLESTADT, 1988; PAK e CHESKY, 2001). No caso do presente estudo, as associações com o gênero foram encontradas nas regiões do ombro direito, o que corrobora com as indicações dos 
autores, uma vez que, estas regiões corporais são as responsáveis pela repetitividade, precisão e velocidade dos movimentos no caso das cordas e, suporte, repetição e velocidade no caso das madeiras e metais.

As associações relacionadas ao tempo e a frequência das práticas instrumentais com as queixas musculoesqueléticas foram evidenciadas no presente estudo no que tange as relações com o pescoço, ombro, punho, região inferior e superior das costas, nos últimos 12 meses e sete dias de práticas (Tabelas 1 e 2). Estas relações foram evidenciadas no estudo de Frank e Mühlen (2007) e de Brandfonbrener (2003). Roset-Liobet, Rosinés-Cubells e Saló-Orfila (2000) que associaram que a mudança (no sentido de aumentar as horas de ensaio) está relacionada ao aparecimento de desconforto, assim como a preparação para os concertos ou para exames. Da mesma forma, Medoff (1999) e Kaneko, Lianza e Dawson (2005) relacionaram o tempo e a frequência dedicada ao instrumento com as queixas apresentadas pelos músicos, o que corrobora com os resultados aqui encontrados.

Van der Windt et al. (2000) relacionaram a carga física e as queixas na região dos ombros. Para Fragelli e Günther (2009) o sentimento de dor indicou presença de maior carga física. Além disso, segundo os autores houve uma relação entre a piora da dor, quando em presença de algum fator que exigisse maior demanda física como, por exemplo, uma postura inadequada, manter-se em uma mesma posição ou, assim como indica Teixeira et al. (2009b) e Teixeira et al. (2009c) carregar o instrumento musical.

Para Roset-Liobet, Rosinés-Cubells e Saló-Orfila (2000) 85,7\% dos músicos acometidos por problemas de saúde apresentam problemas musculoesqueléticos. As regiões anatômicas mais afetadas foram os membros superiores e o pescoço. Bejjani, Kaye e Beham (1996) chamam a atenção para os acometimentos incidentes nos músicos, pois a necessidade de utilização tanto da musculatura flexora quanto extensora pode agravar a situação dos músicos.

As associações mais fortes foram relacionadas às queixas e aos afastamentos nas mesmas regiões musculoesqueléticas o que indica que com os acometimentos há uma tendência em gerar impedimentos das atividades instrumentais (Tabelas 3 e 4). Porém, outras relações foram encontradas no que tange regiões corporais próximas e os afastamentos, como por exemplo, as associações entre os ombros e o pescoço e a região das costas. Essas relações indicam que a sobrecarga em uma região corporal implica em sobrecarga nas demais regiões, principalmente se a musculatura estiver sendo utilizada de forma indevida como ocorre em 
alguns casos que os instrumentistas fazem uso de contrações desnecessárias para a realização dos movimentos.

Com relação aos locais de acometimentos, Lederman (2003) avaliando 1353 instrumentistas reportou prevalências de 64,4\% dos músicos com disfunções musculoesqueléticas nas regiões das mãos, punhos e antebraço. Resultado semelhante obteve Brandfonbrener (2003) que avaliou 2394 músicos, entre os anos de 1985 e 2002, obtendo os locais de maior acometimento os braços, punhos e mãos. Entre 45 músicos da Orquestra Sinfônica da Universidade Estadual de Londrina também foram estudadas a localização dos sintomas musculoesqueléticos e os resultados se assemelham aos encontrados pelo presente estudo. Os resultados mostraram que as regiões anatômicas mais acometidas nos últimos 12 meses foram os ombros $(48,9 \%)$, coluna cervical $(46,7 \%)$, coluna dorsal $(46,7 \%)$ e punhos e mãos $(33,3 \%)$ (TRELHA et al., 2004).

Mesmo com as indicações das relações entre queixas musculoesqueléticas e afastamentos da profissão, a busca por auxílio clínico normalmente é realizada muito tempo após o início do desconforto. No presente estudo, as relações com as queixas relacionaram com a obtenção do diagnóstico médico, mas parece que aqueles que ainda não o possuem são os que relataram menos queixas (Tabela 1).

Roset-Liobet, Rosinés-Cubells e Saló-Orfila (2000) inferem que mesmo sendo os músicos conscientes de seus problemas, a busca por especialistas é feita de forma tardia, o que leva a agravamentos do quadro. Segundo Fry (1986) parece que, de maneira geral, há aceitação da condição por parte dos músicos o que faz com acreditem que é normal sentir dor.

Mesmo que a dor esteja controlada e que os músicos consigam desenvolver suas atividades, é válido lembrar que o tratamento adequado das dores é o fator principal para que não haja progressão do quadro clínico, levando a um acometimento mais severo (TOLEDO et al., 2004; SOUZA e ALMEIDA, 2006). Os sintomas tornam-se mais difíceis de serem gerenciados se o tratamento não for iniciado precocemente. Caso haja incapacitação de realizar as atividades, a probabilidade de recuperação integral diminui (HANSEN e REED, 2006).

Portanto, assim como indicam Toledo et al. (2004), músicos que apresentam danos mais severos não devem ser encorajados a desempenhar suas funções, pois podem demorar ou piorar a recuperação. Além disso, de acordo com os resultados encontrados, é possível dizer que aqueles indivíduos que são acometidos, mesmo em uma região corporal, devem procurar ajuda, uma vez que outras regiões também possam ser acometidas e não só as atividades 
instrumentais podem ser prejudicadas, mas também a própria saúde dos músicos e atividades da vida diária. Para Lederman (2003) os tratamentos cuidadosamente projetados podem fazer com que os músicos voltem a tocar seus instrumentos.

\section{CONCLUSÃO}

O presente estudo permitiu identificar as associações entre as queixas musculoesqueléticas e os afastamentos em função dessas queixas em músicos de orquestra. As associações encontradas foram entre os aspectos sociodemográficos (idade e gênero), de trabalho (tempo e frequência de prática instrumental) e de saúde (se ter diagnóstico médico).

As queixas musculoesqueléticas se mostraram maiores em indivíduos de maior idade, mulheres, indivíduos com maior tempo de prática e que destinavam menos horas às atividades durante a semana. O diagnóstico clínico se mostrou importante, uma vez que, aqueles que o obtiveram foram os que apresentaram queixas musculoesqueléticas. $\mathrm{O}$ tipo de instrumento tocado demonstrou que as maiores associações entre queixas na região superior das costas estão para os instrumentistas de cordas.

Os afastamentos se relacionaram com as queixas, não apenas nas regiões de causas, ou seja, naquelas que deram origem aos mesmos. Houve também associações em outras regiões corporais próximas e os afastamentos, o que demonstra a implicação de sobrecarga em mais de uma região corporal e indica a necessidade de atitudes preventivas e de correção.

\section{REFERÊNCIAS}

BARROS E. N. C.; ALEXANDRE, N. M. C. Cross-cultural adaptation of the Nordic musculoskeletal questionnaire. International Nursing Review, v. 50, n. 2, p. 101-108, 2003.

BEJJANI, F. J.; KAYE, G. M.; BEHAM, M: Musculoskeletal and neuromuscular conditions of instrumental musicians. Archives of Physical Medicine and Rehabilitation, v. 77, p. 406413, 1996.

BLUM, J. AHLERS, J. Ergonomic considerations in violist's left shoulder pain. Medical Problems of Performing Artists. v. 9, n. 1, p. 25-29, 1994.

BRANDFONBRENER, A. G. Musculoskeletal problems of instrumental musicians. Hand Clinics, v. 19, n. 2, p. 231-239, 2003. 
ENGQUIST, K.; ØRBAEK, P.; JAKOBSSON, Musculoskeletal pain and impact on performance in orchestra musicians and actors. Medical Problems of Performing Artists, v. 19, n. 2, p. 55-61, 2004.

FISHBEIN, M.; MIDDLESTADT, S. E. The prevalence of severe musculoskeletal problems among male and female symphony orchestra string players. Medical Problems of Performing Artists, v. 4, n. 1, p. 41-48, 1988.

FRAGELLI, T. B. O; GÜNTHER, I. A. Relação entre dor e antecedentes de adoecimento físico ocupacional: um estudo entre músicos instrumentistas. Performance Musical, n. 19, p. 18-23, 2009.

FRANK, A.; MÜHLEN, C. A. V. Queixas Musculoesqueléticas em Músicos: Prevalência e Fatores de Risco. Revista Brasileira de Reumatologia. v. 47, n.3, p. 188-19, 2007.

FRY, H. J. H. Incidence of overuse syndrome in the symphony orchestra. Medical Problems of Performing Artists, v. 1, n. 2, p. 51-55, 1986.

HANSEN, P. A.; REED, K. Common Musculoskeletal Problems in the Performing Artist. Physical Medicine and Rehabilitation Clinics of North America, v. 17, p. 789-801, 2006.

HEMING, M. J. E. Occupational injuries suffered by classical musicians through overuse. Clinical Chiropractic, v. 7, p. 55-66, 2004.

KANEKO, Y.; LIANZA, S.; DAWSON, W. J. Pain as an incapacitating factor in symphony orchestra musicians in São Paulo, Brazil. Medical Problems of Performing Artists, v. 20, n. 4, p. 168-174, 2005.

LEDERMAN, R. J. Neuromuscular and musculoskeletal problems in instrumental musicians. Muscle \& Nerve. v. 27, n. 5, p. 549-561, 2003.

MALINA, R. M. Tracking of physical activity and physical fitness across the lifespan. Research Quarterly for Exercise \& Sport, v. 67, p. 48-57, 1996.

MEDOFF, L. E. The Importance of movement education in the training of young violinists. Medical Problems of Performing Artists, v. 14, n. 4, p. 210-219, 1999.

MENDES, M. H.; CATAI, R. E.; ALBERTI, M. E. Avaliação dos níveis de pressão sonora aos quais músicos de uma banda estão expostos. Revista Produção Online, v. 9, n. 2, p. 264283, 2009.

MIDDLESTADT, S. E.; FISHBEIN, M. The prevalence of severe musculoskeletal problems among male and female symphony orchestra string players. Medical Problems of Performing Artists, v. 4, n. 1, p. 41-48, 1989.

NORRIS, R. The musician's survival manual: a guide to preventing and treating injuries in instrumentalists. 3. ed. St. Louis, MO: MMB Music, 1997. 
PAK, C. H,; CHESKY, K. Prevalence of hand, finger and wrist musculoskeletal problems in keyboard instrumentalists: the University of North Texas Musician Health Survey. Medical Problems of Performing Artists, v. 16, n. 1, p. 7-23, 2001.

PINHEIRO, F. A.; TRÓCCOLI, B. T.; CARVALHO, C. V. Validação do Questionário Nórdico de Sintomas Osteomusculares como medida de morbidade. Revista de Saúde Pública, v. 36, n. 3, p. 307-12, 2002.

POTTER, P. J.; JONES, I. C. Medical problems affectIng musiclans. Canadian Famnilty Physician, v. 41, p. 2121-2128, 1995.

ROSSET-LLOBET, J.; ROSINÉS-CUBELLS, D.; SALÓ-ORFILA, J. M. Identification of risk factors for musicians in Catalonia (Spain). Medical Problems of Performing Artists, v. 15, n. 4, p.167-74, 2000.

SADEGHI, S.et al. A high prevalence of cumulative trauma disorders in Iranian instrumentalists. BMC Musculoskeletal Disorders, v. 5, n. 35, p. 1471-1474, 2004.

SCHUELE, S. U.; LEDERMAN, R. J. Occupational disorders in instrumental musicians. Medical Problems of Performing Artists, v. 19, n. 3, p. 123-128, 2004.

SOUZA, G. M.; ALMEIDA, F. S. Queixa de dor músculo-esquelética das atletas de 6 a 20 anos praticantes de ginástica artística feminina. Arquivos Médicos do ABC, v. 31, n. 2, p. 67-72, 2006.

STEINMETZ, A.; SEIDEL, W.; NIEMIER, K. Shoulder pain and holding position of the violin. Medical Problems of Performing Artists, v. 23, n. 2, p. 79-81, 2008.

TEIXEIRA, C. S.et al. Trabalho e prática de exercícios físicos: o caso de músicos de orquestra. Lecturas Educación Física y Deportes, v. 13, n. 130, 2009a.

http://www.efdeportes.com/efd130/exercicios-fisicos-o-caso-de-musicos-de-orquestra.htm

TEIXEIRA, C. S.I. et al. Características cinéticas durante a marcha de um músico com e sem o transporte de seu instrumento. Revista Brasileira de Cineantropometria \& Desempenho Humano, v. 11, n. 1, p. 43-50, 2009b.

TEIXEIRA, C. S. et al. O equilíbrio de um músico com e sem o transporte de seu instrumento. Fisioterapia em Movimento, v. 22, n. 1, p. 37-43, 2009c.

THOMAS, J. R.; NELSON, J. K. Métodos de pesquisa em atividade física. Porto Alegre: ArtMed, 2002.

TOLEDO, S. D.et al. Sports and Performing Arts Medicine. 5. Issues Relating to Musicians. Archives of Physical Medicine and Rehabilitation. v. 83, n. 3, p. 72-74, 2004.

TRELHA, C. S. et al. Arte e Saúde: Freqüência de sintomas músculo-esqueléticos em músicos da orquestra sinfônica da Universidade Estadual de Londrina. Semina: Ciências Biológicas e da Saúde. v. 25, p. 65-72, 2004. 
WINDT, D. A. W. M. et al. Occupational risk factors for shoulder pain: a systematic review. Occupational and Environmental Medicine, v. 57, p. 433-442, 2000.

WU, S. J. Occupational Risk Factors for Musculoskeletal Disorders in Musicians: A Systematic Review. Medical Problems of Performing Artists, v. 22, n. 2, p. 43-51, 2007.

ZAZA, C.; FAREWELL, V. T. Musicians' playing-related musculoskeletal disorders: An examination of risk factors. American Journal of Industrial Medicine, v. 32, p. 292-300, 1997.

ZAZA, C. Playing-related musculoskeletal disorders in musicians: a systematic review of incidence and prevalence. Canadian Medical Association Journal. v. 21, n. 8, p. 1019-1025, 1998.

ZAZA, C.; CHARLES, C.; MUSZYNSKI, A. The meaning of playing-related musculoskeletal disorders to classical musicians. Social Science \& Medicine, v. 47, n. 12, p. 2013-2023, 1998. 